\title{
Research on Conflict Behavior of Top Management Team in Family Enterprises: A Complex Network Perspective
}

\author{
Mengyun Wu, ${ }^{1}$ Huimin $W u,{ }^{1}$ Tao Xie, ${ }^{2}$ and Jie $\mathrm{Lu}^{2}$ \\ ${ }^{1}$ School of Finance \& Economics, Jiangsu University, Zhenjiang 212013, China \\ ${ }^{2}$ School of Management, Jiangsu University, Zhenjiang 212013, China \\ Correspondence should be addressed to Mengyun Wu; luguanlan@vip.163.com
}

Received 12 March 2015; Accepted 2 July 2015

Academic Editor: Xavier Delorme

Copyright (c) 2015 Mengyun Wu et al. This is an open access article distributed under the Creative Commons Attribution License, which permits unrestricted use, distribution, and reproduction in any medium, provided the original work is properly cited.

\begin{abstract}
At present time, methods of research about top management team's conflict become more and more prosperous with the help of complex system theory and evolutionary game. Taking family enterprise as an example, this paper makes an attempt on exploring complex network modeling to study data processing method and abstraction method of complex network of TMT conflict. And the paper will consider the attribute and relational mapping of top management team as nodes and edges in complex network to discuss the direct correspondence between complex network structure and management team characteristics. Besides that, according to the multiple attribute decision making, the method to dig into core members of the top management team will be created on the basis of the degree, closeness, cluster coefficient, and betweenness. And then the article will devote to studying the impact of attributes to the inner mechanism of TMT conflict and team cohesion through the network characteristic analysis.
\end{abstract}

\section{Introduction}

In the era of knowledge-based economy society, as one of the decisive factor to get sustained viability and greater market development of family enterprises, conflict of top management team attracts more and more attention. Social investigation and mathematical statistics are usually adopted as basic tools in traditional research to discuss TMT (top management team) conflict and analyze the relationship between team performance and the motivation. In recent years, there is little progress in the description of nonlinear properties, microscopic mechanism, and interaction process of the TMT conflict. Different from the overall top-down research method, this paper tries to make use of grounded theory research method to describe attributes, microscopic behavior, and macrobehavior of TMT conflict with tools of complex network and multiagent complex system model. And finally the author will discuss the process and mechanism of team conflict and its influence on the cohesion and team performance from different perspectives.

\section{Analysis on Static Network Characteristics of TMT Conflict in Family Enterprises}

2.1. Network Relational Mapping of TMT in Family Enterprises. According to self-organization characteristics of family enterprises, TMT members' constitution has the characteristics of knowledge complementarities, special affiliation subordination, and specific properties of demography and task other than normal organization. As a result, the paper considers individual members in family enterprises as different network nodes. Furthermore, the relationship between member $A$ and member $B$ will be treated as the connection of nodes. On the basis of it, we can describe the relationship among team members with the help of network diagram. This paper will reveal the intrinsic link between team members' personal and relational information effectively and find out the effective mechanism of how the link influences the conflict through further analysis.

TMT members in family enterprise play important roles of conflict body in decision making and program 
delivering. The network analysis and abstraction of conflict should be based on the attribute extraction of team members [1]. The attributes of key members that affect the conflict will be shown by a collection of $F=$ \{age, education, relationship, role...\} $[2,3]$; we can define $F=$ $\left\{f_{i} \mid i \in N\right\}$. And various properties of team members $f_{i}$ are listed by using enumeration. For example, $\{0,1,2,3\}$ can be used to describe the relationship attributes of TMT members, and 0 means relationship is not so good, 1 means just ordinary, 2 means good, and 3 means relatives; similarly, when $\{0,1,2,3\}$ is used to refer to education, it shows that 0 refers to primary education, 1 refers to high school education, 2 refers to college education, and 3 refers to graduate and doctoral education.

What a team should focus on are task and relationship. Thus, the internal conflict relationship among TMT members under the real conditions contains task conflict (TC) and relationship conflict (RC) $[1,4]$. These two different relationship types can be shown by the finite set $\{$ TC, RC\}, and their corresponding color set is $C=\{$ red, green $\}$ which is denoted as $C=\{r, g\}$. In addition, by using a quad $G=(V, C, R, F)$, the paper will describe the relationship network of TMT members in detail.

$V=\left\{v_{1}, v_{2}, \ldots, v_{n}\right\}$ suggests network node set. The elements of $V$ shown by ordinal values $n \in N$ represent TMT members. And the value of set $V$ determines the size of the team. In other words, more nodes means more complicated team relationships.

$C$ refers to coloring schemes $\{r, g\}$ which are corresponding to relationships. The color of red means task conflict (TC) and green represents relationship conflict (RC).

$R=\left\{r_{i j c} \mid i, j \in N, i \neq j, c \in C\right\}$ is a set which refers to members relationship. The manifestation of task conflict (TC) in this set is color edge, that is, from member $j$ to member $i$, which means $j$ and $i$ are connected. Meanwhile, the manifestation of relational conflict (RC) is bidirectional color edge between $j$ and $i$, which represents interpersonal relationship of member $i$ and member $j$.

$F$ is the attribute value matrix for TMT members and its element $f_{i j}$ means attribute values $P_{j}$ of TMT member $i$.

Therefore, this network can be defined in the form of the adjacency matrix as formula (1) below:

$$
\begin{aligned}
& A=\left\{\mathbf{a}_{i j}\right\}_{N \times N} \\
& = \begin{cases}\mathbf{a}_{i j}=s(i, j, r) \mathbf{r}+s(i, j, g) \mathbf{g}, & i \text { connected with } j, \\
0, & i, j \text { is not conected. }\end{cases}
\end{aligned}
$$

In formula (1), $s(i, j, c)$ indicates the number of color edges whose length is 1 and it means nodes $i$ and $j$ are connected. And colors $r$ and $g$ are coloring vectors. It is worth noting that $i, j \in n(V)$ and $c \in C$.

Due to the basic concept of graph theory $[5,6]$, the finite sequence $W_{k}=\left(v_{0}, v_{1}, v_{2}, \ldots, v_{n}\right)$ is called the $K$ th path from $v_{i}$ to $v_{n}$. Therefore, we can count $W_{\left(i_{0}, i_{k}, c\right)}=$ $\left(r_{i_{0} i_{1} c}, r_{i_{1} i_{2} c}, \ldots, r_{i_{k-1} i_{k} c}\right)$ as a path whose color is $c$ from $i_{0}$ to $i_{k}$ in the TMT relationship network. If each side and each node of path $W_{\left(i_{0}, i_{k}, c\right)}$ are all different, this path will be called Hamilton [7]. And the existence of $W_{(i, j, c)}$ in the network means that that nodes $i$ and $j$ have relationship with $c$ color. The path with shortest length which connects $i$ and $j$ is noted as the shortest path $d(i, j, c)$.

\subsection{The Analysis of Network Attributes of TMT in Family} Enterprises. If we can promptly determine the key personnel who definitely influence cohesion of TMT and focus on how to deal with them it will be possible to reduce the potential conflicts and improve TMT efficiency [8]. Based on the accomplishment of complex network mapping of TMT, the paper chooses four properties indexes, which consist of degree, closeness, cluster coefficient, and betweenness, and tries to set up correlation between characteristics of TMT and specialty of complex networks. Finally, by analyzing these four properties, we can efficiently obtain nonlinear information and situation of TMT network and digest core information about TMT conflict effectively [9].

\subsubsection{Network Attributes of Top Management Team}

(1) Degree. Degrees can be defined as the numbers of edges connected to the node $v_{i}$, which are the basic characteristics of the network nodes. And, in this paper, the degree of TMT relational network can be seen as vector sum of different color edges associated with $v_{i}$. Consider

$$
\mathbf{k}(\mathbf{i})=k(i, r) \mathbf{r}+k(i, g) \mathbf{g} .
$$

In formula (2), we consider the numbers of different color edges which are connected with $v_{i}$ as color $C$, and they will be calculated with the following formula:

$$
k(i, c)=\sum_{j=0, i \neq j}^{n(V)} s(i, j, c), \quad c \in C=\{r, g\} .
$$

With the help of adjacency matrix properties of $N$ order simple undirected graph $G$, the main diagonal elements $c_{i i}$ of matrix $C\left(C=A^{2}=\left\{c_{i j}\right\}_{N \times N}\right)$ can be expressed as

$$
c_{i i}=\sum_{j=1}^{N} a_{i j} a_{j i}=\sum_{j=1}^{N} a_{i j}^{2}=\sum_{j=1}^{N} a_{i j}=k_{i} .
$$

We can know easily that $c_{i i}$ is the degree of corresponding node $v_{i}$.

The importance of the node can be shown through the value of nodes degrees. In other words, the node with high degrees in the network means the member has a complex interpersonal relationship with others in the task and human communication. So these members should be skilled in the management experience, communication skills and technical level; otherwise lacking of all these skills might result in the task or interpersonal conflict easily [10]. So the node can be considered as the core reference characteristics of potential conflict in top management team.

(2) Closeness. We use closeness to measure the centric degree of nodes according to shortest path. And closeness refers to the reciprocal of the sum of all the shortest distances from 
node $v_{i}$ to others. If $d\left(v_{i}, v_{j}\right)$ are assumed to be the numbers of sides contained in the paths which started from point $v_{i}$ and ended in the terminal point $v_{j}$, the closeness $C_{i}$ of nodes $v_{i}$ can be described as

$$
C\left(v_{i}\right)^{-1}=\sum_{j=1}^{n} d\left(v_{i}, v_{j}\right) .
$$

Based on formula (5), the closeness of TMT network can be known as a vector which consisted of two kinds of colors. And the closeness $C_{i c}$ of color $C$ of node $v_{i}$ can be shown by following formula:

$$
C(i, c)^{-1}=\sum_{j=0}^{n(V)} d(i, j, c) .
$$

The central location of every node in the network depends on the differences of closeness. The larger closeness means more important position. Communication will be more smooth, task transfer will be more convenient, and the conflict will be reduced greatly when network distance becomes small in the task and interpersonal interaction among the TMT members. Therefore, if the closeness of a TMT member is large, he/she will be in the center of the network. His/her strong cohesive force can fully and effectively mobilize and utilize human resources of the team; thus it is beneficial to improve the efficiency of TMT in family enterprise $[11,12]$.

(3) Cluster Coefficient. The relevance characteristics of social capital network are obvious in some sense. For example, your two different acquaintances may also by coincidence be familiar with each other. This kind of network structure which is known as integration can be described as cluster coefficient quantitatively, and cluster coefficient means the connection probability two nodes which are all have connections with another node in the network. Correspondingly, the member with high cluster coefficient will have more complex business relationships and closer human relationships in TMT network. If $E_{c}(i)$ is assumed to be a collection of nodes which are connected with node $v_{i}$ in TMT network, we have the ability to calculate the cluster coefficient of TMT network according to the definition of cluster coefficient:

$$
C C(i, c)=\frac{\sum_{j \in E_{c}(i), d(i, j, c)=1} 2 s(i, j, c)}{\left(E_{c}(i)+1\right)} .
$$

(4) Betweenness. Freeman (1977) $[13,14]$ proposed the concept of betweenness can be considered as global network characteristics. Usually, we use betweenness to identify and measure the effect and influence of nodes or edges in the network. Generally, the high value of betweenness of a member's node indicates that his/her interpersonal interaction channels are also relatively close. As a result, he/she can influence the team performance greatly. The betweenness $B_{i}$ of a Node $v_{i}$ can be defined as the number of the shortest paths which go through node $v_{l}$ between all nonadjacent nodes $v_{j}$ and $v_{k}$. Based on this definition, nodes' betweenness of color $C$ network of TMT can be expressed as

$$
B(i, c)=\sum_{j, k, j \neq k \neq i} N_{j k}(i, c) .
$$

It is important to note that $N_{j k}$ shows the number of the shortest paths between $v_{i}$ and $v_{j}$, and $N_{j k}(i, c)$ represents the number of the shortest paths with color $C$ which go through node $v_{i}$.

2.2.2. Data Processing of Characteristic Attributes. Degree, closeness, cluster coefficient, and betweenness, four characteristic properties which are commonly used to describe TMT network, are usually observed and measured by value of different colors. And due to their vector characteristics, the author has to make further processing before analyzing the core nodes of network. In TMT network, we use $\omega_{r}$ and $\omega_{g}$ to show the weight of task conflict (conflict arising from task) and interpersonal conflict (conflict arising from personal relationship), respectively. The weight vector can be denoted as $\omega=\left(\omega_{r}, \omega_{g}\right) \cdot \omega_{r}+\omega_{g}=1$ will hold without thinking about other factors in the team work. When the family enterprise mainly pays attention to business strategic orientation and task management, the value of $w_{r}$ will be relatively higher; while the family enterprise focuses more on the interpersonal interactions and relationships, the value of $w_{g}$ usually will be relatively higher.

If $p r$ is assumed as a particular attribute value of one company, we can obtain that $\operatorname{pr}(i)=\operatorname{pr}(i, r) \omega_{r}+\operatorname{pr}(i, g) \omega_{g}$. On the basis of all the above, we can construct a matrix $U$, which consists of degree, closeness, cluster coefficient, and betweenness. And standardization is essential with the help of following formula because of different dimension of these attributes.

$$
\operatorname{pr}^{\prime}(i)=\frac{\operatorname{pr}(i)-\min (\operatorname{pr}(i))}{\max (\operatorname{pr}(i))-\min (\operatorname{pr}(i))}, \quad i \in n(V) .
$$

After calculation with formula (9), we are able to obtain matrix $V$ which is standardized from matrix $U$. In addition, the canonical matrix also needs normalization processing to simplify calculation. Consider

$$
\operatorname{pr}^{\prime \prime}(i)=\frac{\operatorname{pr}(i)}{\sum_{i=1}^{n(V)} \operatorname{pr}(i)}
$$

Finally we can obtain the normalized matrix $Y$.

2.3. The Method to Mine Core Nodes of TMT Relation Network in the Family Enterprise. The team leadership which is a key factor to influence the team cohesion determines that the author should look for the core nodes of TMT network. System science [15] believed that the importance of network nodes is equivalent to its destructiveness, so we should observe how the node removal influences network connectivity based on system function. However, social network research [16] thought that the importance of the node is equivalent to its significance. So we should collect the effective information in the network under the condition of network connectivity to analyze the differences among the nodes so as to count and calculate the degree and betweenness of nodes and finally confirm quantitatively the importance of nodes in the network. 
2.3.1. The Sequence of Node Weight. According to the definition and analysis of the degree, we could know that if you want to estimate the importance of a node, it is best to measure it from the perspective of global network. Besides, the value of the degree of adjacent nodes is equally important. It is assumed that $N_{i}$ refers to a collection of nodes which are adjacent to node $i$, and $w_{i j}$ can be seen as the weight between node $i$ and its adjacent node $j$. It is easy to infer from these definitions that $w_{i j}=w_{j i}=\left(k_{i} k_{j}\right)^{\theta}$ in a simple undirected network. In this formula $k_{i}$ is defined as the degree of node $i, k_{j}$ means the degree of node $j$, and $0 \leq \theta \leq 1$ is a control parameter. Based on it, the node weight $s_{i}$ of node $i$ can be expressed as

$$
s_{i}=\sum_{j \in N_{i}}\left(k_{i} k_{j}\right)^{\theta} .
$$

If it is difficult to estimate the importance of the relationship between two nodes; we can assume the value of $\theta$ is 0 . According to the degree of nodes it can be easy to calculate vertex weight. It is known to be $S$-node. The node weight of TMT network includes two dimensions which are workrelated network and human network. Therefore, we are able to find out position features and importance of each node in different relational network.

\subsubsection{The Sequence of Multiple Attribute Decision Making.} Four properties which are degree, closeness, cluster coefficient, and betweenness can be used to elaborate the characteristics of the network nodes from different sides. So we can establish characteristic attribute value matrix $U$, standardization matrix $V$, and normalization matrix $Y$ to evaluate the importance of TMT network node under complicated environment based on Multiple Attribute Group Decision Making Theory. Ordered weighted geometric (OWG) operator described as $R\left(v_{1}, v_{2}, v_{3}, v_{4}\right)=\sum_{j=1}^{4} x_{j}^{w_{j}}$ will be used for collecting attributes. In this formula, $x_{j}$ means $j$ maximum element of a column's data in the matrix $V$, and $\omega=$ $\left(\omega_{1}, \omega_{2}, \omega_{3}, \omega_{4}\right)^{T}$ refers to the index weighting vector which connects with $R$. In addition, what we need to note is the fact that $w_{j} \in[0,1]$ and the value of $\sum_{j=1}^{4} \omega_{j}$ is 1 . So we can get $\omega$ :

$$
\begin{aligned}
\omega_{i j}= & \frac{1}{\sum_{j=1}^{4}\left[1 / \sum_{i=1}^{n(I)} 2\left(y_{i j}-1\right)^{2}\right]} \\
& \times \frac{1}{\sum_{i=1}^{n(I)} 2\left(y_{i j}-1\right)^{2}} .
\end{aligned}
$$

On the basis of all the above, four values of weight $\omega_{1}, \omega_{2}, \omega_{3}$, and $\omega_{4}$ which will respect the degree, closeness, cluster coefficient, and betweenness, respectively, can be obtained. And we have ability to get an order in matrix $Y$ according to the following formula:

$$
\operatorname{order}(i)=y_{i 1}{ }^{\omega_{1}}+y_{i 2}{ }^{\omega_{2}}+y_{i 3}{ }^{\omega_{3}}+y_{i 4}{ }^{\omega_{4}} \quad i \in n(V) \text {. }
$$

If we can obtain the order relationship with the help of formula (13), it will be easy to sort these network nodes and find the position attributes of a node consisting of degree, closeness, cluster coefficient, and betweenness. Then, it is possible for us to find out key members of TMT, analyze the position of each member in the network, and explore the underlying cause of the conflict.

The members of Family Business's TMT have individual differences and their behavior is dynamic, while the individual members have the abilities of self-learning and selfadaption and are able to adjust their behavioral decision making based on their own experience and the interaction with the other members in the later work; thus, the conflict between team members is complex management problems; it has a nonlinear characteristic. This study pays attention to making a comparison between the different values of sequence calculated through node weight sorting and multiple attribute decision making sorting to identify and measure the position and role of the members in the team.

\section{The Calculation Model and Experimental Analysis}

3.1. The Model for Calculating. According to the definition of the attributes and operator algorithm, we can divide the calculation model into several steps. Firstly, draw TMT network graph and calculate characteristic attribute of two color vectors. Secondly, construct attribute value matrix by the weights of two colors (red and green); these two colors represent task conflict and relationship conflict, and also construct attribute value matrix by the weights of two colors. Thirdly, through normative approach and normalization processing, establish the standard matrix and the normalized matrix. Finally, count the value of weight and sort the attribute value, and precisely describe the key nodes [17, 18]. The calculation model to judge and look for the key node of top management team network is shown in Figure 1.

3.2. Background of $E$ and $F$ Enterprises. Two relatively big family enterprises which are included in mobile communication products distribution industry and produce mobile communication products are located in Yangtze River delta region. Due to typical attributes, they are chosen as examples in this paper. For the convenience of research, we refer to the sample enterprises as $E$ enterprise and $F$ enterprise. The method of comparative study of two case companies was adopted in this paper. In addition, we collect relevant materials and interview not only a manager who has worked in $E$ and $F$ companies successively, but also one present TMT member in each company, and to interview them both for three times. Semistructured interview method is used in these interviews. Under the guidance of the researchers, interviewees introduce in detail the background of the two companies, TMT members, personality and leadership style of CEO, and the specific operation process within TMT, such as internal communication, conflict, decision making, and the performance of the company [19]. From Table 1 we can make a comparison between two family enterprises.

Like many other private mobile phone enterprises, enterprise $E$ develops rapidly at the beginning by selling smuggled 
TABLE 1: Background description of $E$ and $F$ enterprises.

\begin{tabular}{lll}
\hline & $E$ & $F$ \\
\hline Time of company's foundation & 1996 & 1998 \\
\hline Corporation nature & $\begin{array}{l}\text { Family business, restructured as large state-owned } \\
\text { joint venture company in 2004, used to engage in } \\
\text { mobile phone distribution, now operates as } \\
\text { limited liability company }\end{array}$ & Family business, now operating as Co., Ltd. \\
\hline Brand agency & $\begin{array}{l}\text { First-line brand of mobile phones, such as } \\
\text { Samsung, Motorola, and HTC }\end{array}$ & $\begin{array}{l}\text { Second- and third-line brand of mobile } \\
\text { phones, such as LG, Lenovo, ZTE, and Tianyu }\end{array}$ \\
\hline Major markets & $\begin{array}{l}\text { Concentrated in the Yangtze River Delta region, } \\
\text { mainly in Jiangsu Province }\end{array}$ & $\begin{array}{l}\text { Nationwide, especially focus on relatively small } \\
\text { city in Zhejiang Province }\end{array}$ \\
\hline Main business operation & $\begin{array}{l}\text { Engage in mobile phone sales agent service and } \\
\text { telecom service }\end{array}$ & $\begin{array}{l}\text { Engage in China mobile business sales agent } \\
\text { service, such as mobile phone sales agent, } \\
\text { telecom service, and cross industry investment }\end{array}$ \\
\hline Operating conditions & $\begin{array}{l}\text { Performance is stable; sales of 3.1 billion yuan in } \\
\text { 2007 }\end{array}$ & $\begin{array}{l}\text { Sales income is 3.4 billion yuan in 2007 and } \\
\text { then losses due to the volatile market changes }\end{array}$ \\
\hline
\end{tabular}

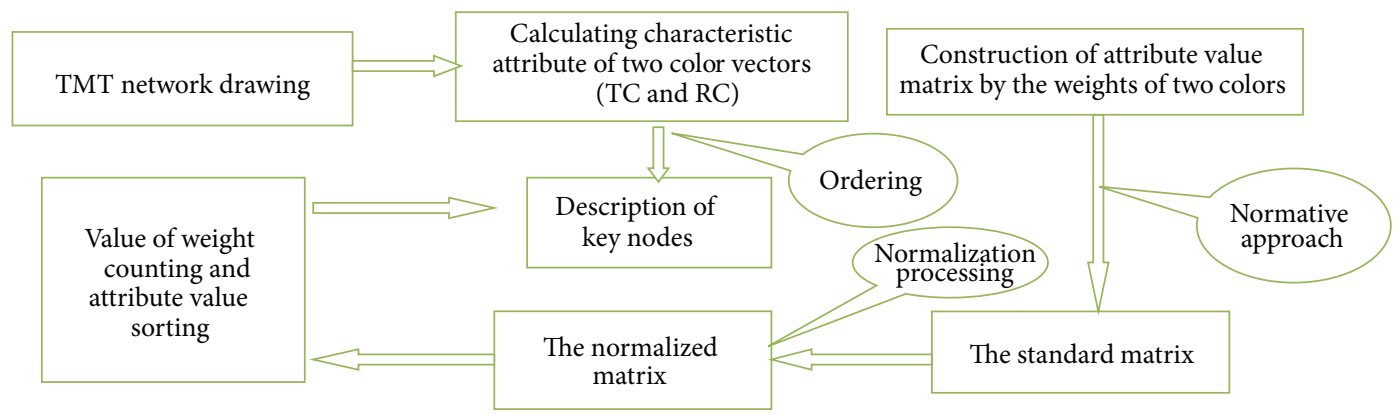

FIGURE 1: Evaluation model of network attribute.

mobile phone and related telecom products. Enterprise $E$ has focused its attention on distributing mobile phone through agents since 1996. Relying on diversified and longitudinal alliance strategy and close cooperation with the upstream entities, enterprise $E$ has finally become a joint venture company of state-owned enterprises and builds up a relativesound organizational structure in 2004. Enterprise $E$ is a sales agent of the first-line mobile phones at present and takes the lead in the relevant field. Meanwhile, $F$ enterprise mainly sells second- and third-line mobile phones. After its accumulation and expand as well as external cooperation with upstream resources, $F$ enterprise has a larger market in the second- and third-tier cities by taking the advantage of traditional sales channels. Table 2 shows the two companies' TMT members and Table 3 illustrates the comparison of features between two enterprise TMT members.

Table 3 tells us that the TMT of $E$ and $F$ enterprises is all made up of the family members, senior staffs, and professional managers. In addition, the time point they founded is very near; that means these 2 enterprises have similar characteristics. However, the feature of 2 enterprises is different in the development scale, marketing, and management. For example, some key positions in $E$ enterprise are held by professional managers, which ensure that they could efficiently play their role and work very well. And it can be implicated easily that the influence of family members on family enterprise has been weakened gradually.
Meanwhile, the assistant president of $F$ enterprise tends to control and operate the company with centralized and standardized management. And the function and importance of the professional managers were overlooked, which resulted in high turnover rate. Thus, two cases in this paper have distinctive characteristics and are directly comparable.

The members of Family Business's TMT have individual differences and their behavior is dynamic, while the individual members have the abilities of self-learning and selfadaption and are able to adjust their behavioral decision making based on their own experience and the interaction with the other members in the later work; thus, the conflict between team members is complex management problems; it has a nonlinear characteristic. Compared to family enterprise $E$, enterprise $F$ selects the beeline function style as organization structure, which takes the place of a complete governance structure such as board of directors and supervisory board. So the cohesiveness of the TMT is relatively poor. Though enterprise $F$ introduced professional managers of different demography characteristics continuously, most of times they could not cooperate with family members and senior staffs in TMT very well. As a result, conflicts occurred among factions from time to time and often transfer from task conflict to relational conflict $[20,21]$. In addition, the CEO, one of the most important members in top management team, is not able to deal with the TMT conflicts among different type's members very justly. As a result, it is difficult to attain a 
TABLE 2: Comparative analysis on composition of TMT in $E$ and $F$ enterprises.

\begin{tabular}{|c|c|c|c|c|c|}
\hline \multicolumn{3}{|c|}{$E$} & \multicolumn{3}{|c|}{$F$} \\
\hline Sequence & Position & ID & Sequence & Position & ID \\
\hline 01 & President & Group accredited & 01 & $\begin{array}{c}\text { President and } \\
\text { general manager }\end{array}$ & Company founder \& CEO \\
\hline 02 & CEO & $\begin{array}{l}\text { Company founder and } \\
\text { administrative } \\
\text { manager } \\
\end{array}$ & 02 & $\begin{array}{l}\text { Executive deputy } \\
\text { general manager }\end{array}$ & $\begin{array}{l}\text { Family member (in charge of } \\
\text { finance, logistics management, } \\
\text { personnel, etc.) }\end{array}$ \\
\hline 03 & $\begin{array}{l}\text { Assistant general } \\
\text { manager }\end{array}$ & Professional manager & 03 & Assistant president & Professional manager \\
\hline 04 & $\begin{array}{l}\text { Deputy general } \\
\text { manager }\end{array}$ & Professional manager & 04 & $\begin{array}{c}\text { Administrative } \\
\text { personnel manager }\end{array}$ & Professional manager \\
\hline 05 & Finance director & Professional manager & 05 & Technical manager & Professional manager \\
\hline 06 & Internal consultant & Family member & 06 & Sales manager & Professional manager \\
\hline 07 & Marketing director & Senior staff & 07 & $\begin{array}{l}\text { Financial } \\
\text { department } \\
\text { manager }\end{array}$ & Professional manager \\
\hline 08 & Marketing manager & Senior staff & 08 & Finance director & Senior staff \\
\hline 09 & Sales manager & Senior staff & 09 & $\begin{array}{l}\text { Logistics } \\
\text { department } \\
\text { manager }\end{array}$ & Family member \\
\hline 10 & $\begin{array}{l}\text { Financial } \\
\text { department } \\
\text { manager }\end{array}$ & Senior staff & & & \\
\hline 11 & $\begin{array}{c}\text { Development } \\
\text { manager }\end{array}$ & Senior staff & & & \\
\hline 12 & IT manager & Senior staff & & & \\
\hline
\end{tabular}

TABLE 3: Comparative analyses on TMT attributes of $E$ and $F$ enterprises.

\begin{tabular}{lll}
\hline & $E$ & $F$ \\
\hline $\begin{array}{l}\text { Corporate governance } \\
\text { structure }\end{array}$ & $\begin{array}{l}\text { Relatively perfect and consists of the board of } \\
\text { directors and supervisory board }\end{array}$ & $\begin{array}{l}\text { Relatively lack of corporate governance, the board } \\
\text { exists in name only, CEO also functions as president } \\
\text { and general manager }\end{array}$ \\
\hline Educational background & $\begin{array}{l}\text { Internal consultant is a professional and well-known } \\
\text { expert; assistant general manager, finance director, } \\
\text { and marketing manager all obtained bachelor degree; } \\
\text { and the educational background of other members in } \\
\text { TMT is college or below }\end{array}$ & $\begin{array}{l}\text { Assistant president and mobile department director } \\
\text { all obtained bachelor degree; others' degree is college } \\
\text { or below }\end{array}$ \\
\hline Age range & $\begin{array}{l}\text { They are all over 35 years old and less than 57; the } \\
\text { average age is 44.2 }\end{array}$ & $\begin{array}{l}\text { They are all over 39 years old and less than 63; the } \\
\text { average age is 48.1 }\end{array}$ \\
\hline $\begin{array}{l}\text { PEOfessional } \\
\text { backgrounds }\end{array}$ & $\begin{array}{l}\text { director majors in accounting; professional managers } \\
\text { all major in related specialty, and others have no } \\
\text { relevant professional background }\end{array}$ & $\begin{array}{l}\text { Finance director has previous related financial career } \\
\text { background; professional managers have previous } \\
\text { related career background; other executives in TMT } \\
\text { have no relevant professional background }\end{array}$ \\
\hline $\begin{array}{l}\text { Their terms are all long which are usually longer than } \\
7 \text { years; the active turnover of company veteran is low, } \\
\text { especially core executives worked in the finance and } \\
\text { sales department }\end{array}$ & $\begin{array}{l}\text { Their terms are all short which are not longer than } 5 \\
\text { years; the active turnover of company veteran and } \\
\text { professional manager is high; for example, finance } \\
\text { department manager and sales manager changed } \\
\text { frequently }\end{array}$ \\
\hline
\end{tabular}

consensus; at the same time, the loyalty and cohesion of the enterprise continue to decline the team effectiveness and affect the team harmony [22-24].

It can be learned and founded from the interview that those members of TMT whose cohesiveness is strong often make decisions by considering collective interests in the family enterprise $E$, although there are conflicts among teams in daily operating. And with the mechanism of regular meeting the members of the TMT can communicate with each other effectively. The CEO is reasonable and a good 


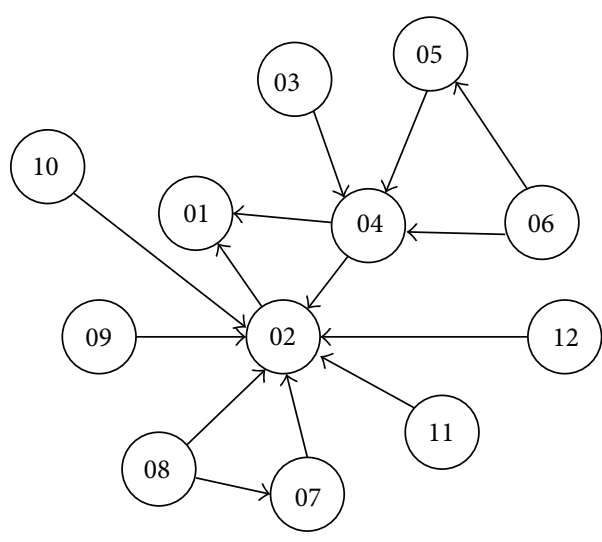

(a) Task relationship ( $r$ color)

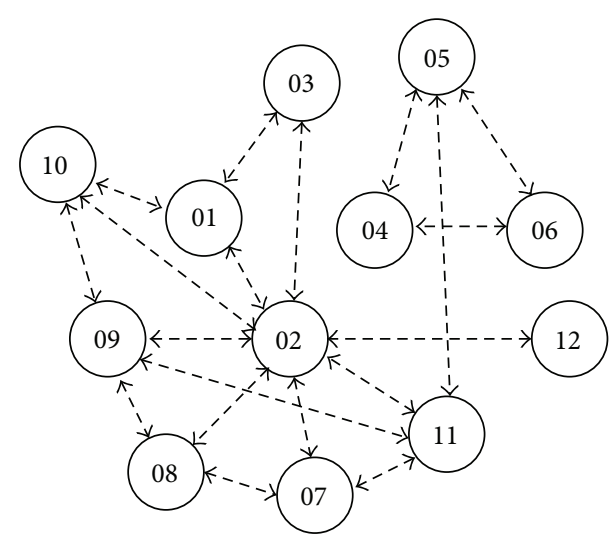

(b) Interpersonal relationship ( $g$ color)

FIGURE 2: Structure of TMT relationship network in corporate $E$.

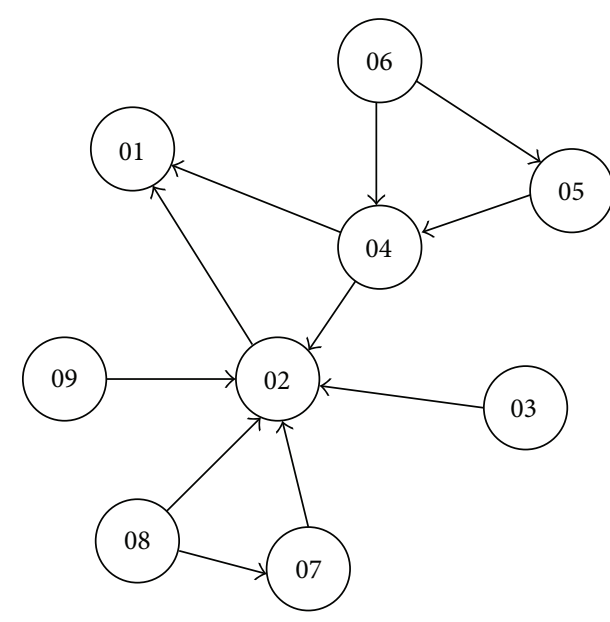

(a) Task relationship ( $r$ color)

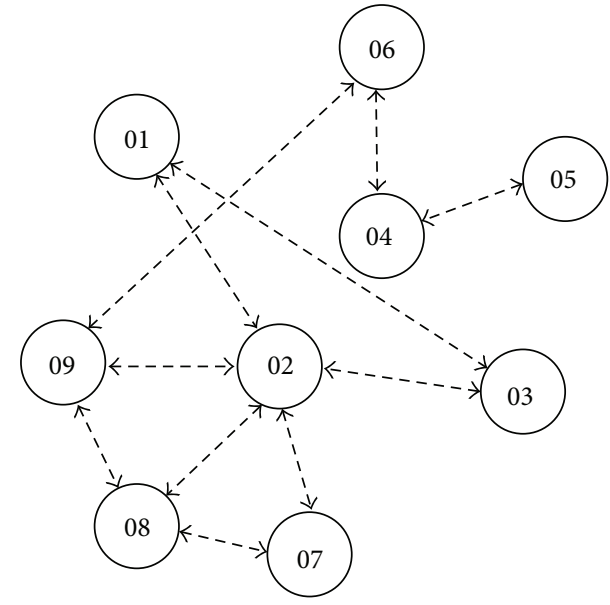

(b) Interpersonal relationship ( $g$ color)

FIGURE 3: Structure of executive team relationship network in corporate $F$.

listener; on one hand, he can take the external professional managers' advice into account and strongly propagate and defend the company policy publicly; moreover, the CEO acts fairly to all employees and deals with the problem with them with all his efforts and makes the members of the TMT more engaged in their job in order to facilitate the reform.

3.3. Calculation and Analysis of the Case. Interview results show that members of TMT in $E$ and $F$ enterprises can be divided into two types such as working relationship and interpersonal relationship. The relation network of TMT in $E$ and $F$ enterprises can be presented in Figures 2 and 3. $r$ color map is shown by solid lines, and the arrows in it refer to work point. $g$ color map is drawn by dotted lines and the bidirectional arrows indicate strong interpersonal relationship. The working relationship in this paper comes from the case written in previous section and the network model is expressed using no-weight and undirected network.

The personnel composition in TMT is shown by the node in Figures 2 and 3 (it is described in detail in Table 2). And we use index method (p1, p2, p3, p4, p5, and p6) to describe some basic properties P of the TMT members. They, respectively, stand for service life, education degree (1 means undergraduate and below, 2 means bachelor degree, 3 means master degree, and 4 means doctor degree), wages (A total of 1 to 10 , the maximum is 10 ), the overall trust (value of selfevaluation, A total of 1 to 10,10 is maximum level), the degree of cooperation (value of self-evaluation, A total of 1-10, the maximum is 10), and the communication level (value of selfevaluation, A total of 1-10, the maximum is 10 ). Based on attributes of all TMT members in $E$ and $F$ enterprises we can obtain attribute matrix $F_{e}$ and $F_{f}$.

Different values of $\omega=\left(\omega_{r}, \omega_{g}\right)$ represent the diverse operation environment of the team. From Tables 4-7 we can know that when $\omega=(0.8,0.2)$ means that the work of the team is on operation, the team's priority is to develop the business. Task conflict accounts for a large proportion on team conflict correspondently; on the other hand, when $\omega=$ $(0.2,0.8)$, the proportion of personal relationships in the team is bigger and the potential conflict is relationship conflict.

When task is in equilibrium with interpersonal relationship and $\omega=(0.5,0.5)$, we can learn from decisive matrix 
TABLE 4: Network attributes of TMT in $E$ enterprise.

\begin{tabular}{|c|c|c|c|c|c|c|c|}
\hline Name & Subsequence & $F_{e}$ & Degree & Closeness & Cluster coefficient & Betweenness & S-node \\
\hline WWY & 01 & $(6,3,10,9,10,10)$ & $2 r+3 g$ & $20 r+24 g$ & $1 r+0.6667 g$ & $0 r+0 g$ & $26 r+39 g$ \\
\hline $\mathrm{SHJ}$ & 02 & $(16,2,9,10,9,10)$ & $8 r+8 g$ & $14 r+16 g$ & $0.0714 r+0.2500 g$ & $36 r+25 g$ & $112 r+184 g$ \\
\hline ZQM & 03 & $(9,2,6,7,8,9)$ & $1 r+2 g$ & $27 r+25 g$ & $0 r+1 g$ & $0 r+0 g$ & $5 r+22 g$ \\
\hline ZJ & 04 & $(6,3,8,10,9,9)$ & $4 r+2 g$ & $17 r+33 g$ & $0.20000 r+1 g$ & $36 r+0 b$ & $75 r+10 g$ \\
\hline SZF & 05 & $(4,2,6,8,8,10)$ & $2 r+3 g$ & $26 r+24 g$ & $1 r+0.3333 g$ & $0 r+32 b$ & $14 r+24 g$ \\
\hline WHC & 06 & $(5,4,4,7,8,8)$ & $2 r+2 g$ & $26 r+33 g$ & $1 r+1 g$ & $0 r+0 g$ & $14 r+10 g$ \\
\hline DHY & 07 & $(14,2,7,9,10,9)$ & $2 r+3 g$ & $23 r+21 g$ & $1 r+0.6667 g$ & $0 r+0 g$ & $20 r+45 g$ \\
\hline LXJ & 08 & $(16,1,3,9,9,10)$ & $2 r+3 g$ & $23 r+24 g$ & $1 r+0.6667 g$ & $0 r+0 g$ & $20 r+45 g$ \\
\hline $\mathrm{CHL}$ & 09 & $(10,1,3,8,8,10)$ & $1 r+4 g$ & $24 r+20 g$ & $1 r+0.5 g$ & $0 r+5 g$ & $8 r+72 g$ \\
\hline $\mathrm{CB}$ & 10 & $(16,1,1,8,8,9)$ & $1 r+3 g$ & $24 r+24 g$ & $0 r+0.6667 g$ & $0 r+0 g$ & $8 r+45 g$ \\
\hline JHX & 11 & $(10,1,2,8,9,10)$ & $1 r+4 g$ & $24 r+18 g$ & $0 r+0.3333 g$ & $0 r+42 g$ & $8 r+72 g$ \\
\hline LGF & 12 & $(13,1,3,7,6,8)$ & $1 r+1 g$ & $24 r+26 g$ & $0 r+0 g$ & $0 r+0 g$ & $8 r+8 g$ \\
\hline
\end{tabular}

TABLE 5: Relationship network attribute decision matrix and sequence $\omega=(0.5,0.5)$ of TMT in $E$ enterprise.

\begin{tabular}{|c|c|c|c|c|c|c|c|c|c|c|c|c|c|}
\hline \multirow{2}{*}{ Number } & \multicolumn{4}{|c|}{$U$} & \multicolumn{4}{|c|}{$V$} & \multicolumn{4}{|c|}{$Y$} & \multirow{2}{*}{ Order } \\
\hline & $D$ & $P$ & $C$ & $B$ & $D$ & $P$ & C & $B$ & $D$ & $P$ & C & $B$ & \\
\hline 01 & 2.5 & 22 & 0.83 & 0 & 0.21 & 0.53 & 0.83 & 0 & 0.0724 & 0.1064 & 0.1187 & 0 & 1.6739 \\
\hline 02 & 8 & 15 & 0.48 & 30.5 & 1 & 1 & 0.48 & 1 & 0.3447 & 0.2008 & 0.0687 & 0.3472 & 2.7142 \\
\hline 03 & 1.5 & 26 & 0.50 & 0 & 0.07 & 0.27 & 0.50 & 0 & 0.0244 & 0.0542 & 0.0716 & 0 & 1.3918 \\
\hline 04 & 3 & 30 & 0.60 & 18 & 0.29 & 0 & 0.60 & 0.59 & 0.0985 & 0 & 0.0858 & 0.2048 & 2.2356 \\
\hline 05 & 2.5 & 25 & 0.67 & 16 & 0.21 & 0.33 & 0.67 & 0.52 & 0.0723 & 0.0663 & 0.0959 & 0.1806 & 2.2339 \\
\hline 06 & 2 & 29.5 & 1 & 0 & 0.14 & 0.03 & 1 & 0 & 0.0492 & 0.0060 & 0.1431 & 0 & 1.3614 \\
\hline 07 & 2.5 & 22 & 0.83 & 0 & 0.21 & 0.53 & 0.83 & 0 & 0.0723 & 0.1064 & 0.1187 & 0 & 1.6737 \\
\hline 08 & 2.5 & 23.5 & 0.83 & 0 & 0.21 & 0.43 & 0.83 & 0 & 0.0723 & 0.0863 & 0.1187 & 0 & 1.6446 \\
\hline 09 & 2.5 & 22 & 0.75 & 2.5 & 0.21 & 0.53 & 0.75 & 0.08 & 0.0723 & 0.1064 & 0.1073 & 0.0278 & 2.0708 \\
\hline 10 & 2 & 24 & 0.33 & 0 & 0.14 & 0.40 & 0.33 & 0 & 0.0493 & 0.0804 & 0.0472 & 0 & 1.4666 \\
\hline 11 & 2.5 & 21 & 0.17 & 21 & 0.21 & 0.60 & 0.17 & 0.69 & 0.0723 & 0.1205 & 0.0243 & 0.2396 & 2.2013 \\
\hline 12 & 1 & 25 & 0 & 0 & 0 & 0.33 & 0 & 0 & 0 & 0.0663 & 0 & 0 & 0.5059 \\
\hline
\end{tabular}

The value of weight of OWG is $0.2498,0.2511,0.2541$, and 0.2477 ; the sequence is $02>04>05>11>09>01>07>08>10>03>06>12$.

TABLE 6: Relationship network attribute decision matrix and sequence $\omega=(0.2,0.8)$ of TMT in $E$ enterprise.

\begin{tabular}{|c|c|c|c|c|c|c|c|c|c|c|c|c|c|}
\hline \multirow{2}{*}{ Number } & \multicolumn{4}{|c|}{$U$} & \multicolumn{4}{|c|}{$V$} & \multicolumn{4}{|c|}{$Y$} & \multirow{2}{*}{ Order } \\
\hline & $D$ & $P$ & C & $B$ & $D$ & $P$ & C & $B$ & $D$ & $P$ & C & $B$ & \\
\hline 01 & 2.8 & 23.2 & 0.73 & 0 & 0.26 & 0.53 & 0.73 & 0 & 0.0765 & 0.0895 & 0.1056 & 0 & 1.6392 \\
\hline 02 & 8 & 15.6 & 0.21 & 27.2 & 1 & 1 & 0.21 & 0.81 & 0.2940 & 0.1686 & 0.0305 & 0.2793 & 2.5211 \\
\hline 03 & 1.8 & 25.4 & 0.80 & 0 & 0.11 & 0.39 & 0.80 & 0 & 0.0324 & 0.0658 & 0.1158 & 0 & 1.5103 \\
\hline 04 & 2.4 & 29.8 & 0.84 & 7.2 & 0.20 & 0.11 & 0.84 & 0.21 & 0.0589 & 0.0185 & 0.1216 & 0.0724 & 2.3818 \\
\hline 05 & 2.8 & 24.4 & 0.47 & 25.6 & 0.26 & 0.45 & 0.47 & 0.76 & 0.0765 & 0.0759 & 0.0680 & 0.2621 & 2.2758 \\
\hline 06 & 2 & 31.6 & 1 & 0 & 0.14 & 0 & 1 & 0 & 0.0412 & 0 & 0.1447 & 0 & 1.0653 \\
\hline 07 & 2.8 & 21.4 & 0.73 & 0 & 0.26 & 0.64 & 0.73 & 0 & 0.0765 & 0.1079 & 0.1056 & 0 & 1.6654 \\
\hline 08 & 2.8 & 23.8 & 0.73 & 0 & 0.26 & 0.49 & 0.73 & 0 & 0.0765 & 0.0826 & 0.1056 & 0 & 1.6283 \\
\hline 09 & 3.4 & 20.8 & 0.60 & 4 & 0.34 & 0.68 & 0.60 & 0.12 & 0.1000 & 0.1147 & 0.0868 & 0.0414 & 2.3818 \\
\hline 10 & 2.6 & 24 & 0.53 & 0 & 0.23 & 0.48 & 0.53 & 0 & 0.0676 & 0.0809 & 0.0767 & 0 & 1.5656 \\
\hline 11 & 3.4 & 19.2 & 0.27 & 33.6 & 0.34 & 0.78 & 0.27 & 1 & 0.1000 & 0.1315 & 0.0391 & 0.3448 & 2.3740 \\
\hline 12 & 1 & 25.6 & 0 & 0 & 0 & 0.38 & 0 & 0 & 0 & 0.0641 & 0 & 0 & 0.5015 \\
\hline
\end{tabular}

The value of weight of OWG is $0.2504,0.2512,0.2513$, and 0.2471 ; the sequence is $02>04=09>11>05>07>01>08>10>03>06>12$. 
TABLE 7: Relationship network attribute decision matrix and sequence $\omega=(0.8,0.2)$ of TMT in $E$ enterprise.

\begin{tabular}{|c|c|c|c|c|c|c|c|c|c|c|c|c|c|}
\hline \multirow{2}{*}{ Number } & \multicolumn{4}{|c|}{$U$} & \multicolumn{4}{|c|}{$V$} & \multicolumn{4}{|c|}{$Y$} & \multirow{2}{*}{ Order } \\
\hline & $D$ & $P$ & $C$ & $B$ & $D$ & $P$ & C & $B$ & $D$ & $P$ & $C$ & $B$ & \\
\hline 01 & 2.2 & 20.8 & 0.93 & 0 & 0.17 & 0.52 & 0.93 & 0 & 0.0691 & 0.1262 & 0.1446 & 0 & 1.7214 \\
\hline 02 & 8 & 14.4 & 0.11 & 33.8 & 1 & 1 & 0.11 & 1 & 0.4065 & 0.2426 & 0.0171 & 0.4311 & 2.6703 \\
\hline 03 & 1.2 & 26.6 & 0.20 & 0 & 0.03 & 0.06 & 0.20 & 0 & 0.0122 & 0.0146 & 0.0311 & 0 & 1.0951 \\
\hline 04 & 3.6 & 20.2 & 0.36 & 28.8 & 0.37 & 0.55 & 0.36 & 0.85 & 0.1504 & 0.1335 & 0.0560 & 0.3664 & 3.0060 \\
\hline 05 & 2.2 & 25.6 & 0.87 & 6.4 & 0.17 & 0.14 & 0.87 & 0.19 & 0.0691 & 0.0340 & 0.1353 & 0.0819 & 2.0836 \\
\hline 06 & 2 & 27.4 & 1 & 0 & 0.14 & 0 & 1 & 0 & 0.0569 & 0 & 0.1555 & 0 & 1.1147 \\
\hline 07 & 2.2 & 22.6 & 0.93 & 0 & 0.17 & 0.37 & 0.93 & 0 & 0.0691 & 0.0898 & 0.1446 & 0 & 1.6727 \\
\hline 08 & 2.2 & 23.2 & 0.93 & 0 & 0.17 & 0.32 & 0.93 & 0 & 0.0691 & 0.0777 & 0.1446 & 0 & 1.6532 \\
\hline 09 & 1.6 & 23.2 & 0.90 & 1 & 0.09 & 0.32 & 0.90 & 0.03 & 0.0366 & 0.0777 & 0.1401 & 0.0129 & 1.9149 \\
\hline 10 & 1.4 & 24 & 0.13 & 0 & 0.06 & 0.26 & 0.13 & 0 & 0.0244 & 0.0631 & 0.0202 & 0 & 1.2687 \\
\hline 11 & 1.6 & 22.8 & 0.07 & 8.4 & 0.09 & 0.35 & 0.07 & 0.25 & 0.0366 & 0.0850 & 0.0109 & 0.1077 & 1.8730 \\
\hline 12 & 1 & 24.4 & 0 & 0 & 0 & 0.23 & 0 & 0 & 0 & 0.0558 & 0 & 0 & 0.4835 \\
\hline
\end{tabular}

The value of weight of OWG is $0.2497,0.2518,0.2518$, and 0.2467 ; the sequence is $04>02>05>09>11>01>07>08>10>06>03>12$.

$U$ obtained from normalization of four attributes that the degree of node 02 is maximal (8.0) and the degree of node 12 is smallest (1.0); the proximity of node 04 is maximal (30.0) and the proximity of node 02 is smallest (15.0); the clustering coefficient of node 06 is maximal (1.00) and the clustering coefficient of node 12 is smallest (0.00); the betweenness of node 02 is maximal (30.5) and the betweenness of nodes 03 , $06,07,08$, and 12 is smallest ( 0 ). It is evident that node 02 gains advantage in a number of characteristics. We can get standard matrix $V$ AND $Y$ through commensurability and normalized processing of matrix $U$ according to formula of (9) and (10). Then average weight value $(0.2498,0.2511,0.2541$, and 0.2498$)$ can be calculated based on formula (11). Four attributes of executive team network will be collected to make use of the value, and the order relation is $12<06<03<10<08<07<$ $01<09<11<05<04<02$.

When $\omega=(0.5,0.5), \omega=(0.2,0.8)$, and $\omega=(0.8,0.2)$ are used in the case, the order relation of attributes is as follows.

When $\omega=(0.5,0.5)$,

order relation of attributes is $02>04>05>11>09>$ $01>07>08>10>03>06>12$;

order relation of node weight is $02>04>09>11>01$ $>07>08>10>05>03>06>12$.

When $\omega=(0.2,0.8)$,

order relation of attributes is $02>04=09>11>05>$ $07>01>08>10>03>06>12$;

order relation of node weight is $02>09=11>07=08$ $>10>01>04>05>03>06>12$.

When $\omega=(0.8,0.2)$,

order relation of attributes is $04>02>05>09>11>$ $01>07>08>10>06>03>12$;

order relation of node weight is $02>04>01>07=08$ $>09=11>05>10>06>03>12$.

It can be seen from Tables 5-7; Enterprise $E$ finished a series of governance of internal structure and established a perfect management system after the successful merger and acquisition with other entities. In addition, the introduction of professional managers $(04,05)$ is able to carry weight. For example, as a member of the professional managers (04), his business ability is strong in the perspective of the individual trait reflected by network attributes, despite the fact that he is from the "outsiders." We can see that he is first in the condition of $\omega=(0.8,0.2)$. And he is the second in $\omega=(0.2,0.8)$, which means that he is good at dealing with others. At the same time, node weight order also suggests that he is critical in the team. All of these factors improve the efficiency of the senior management team. As the initiator of the company (02), he is the second under the condition of task direction $\omega=(0.8,0.2)$, which is in balance with the true ability; however, the member is first under the general conflict $\omega=(0.5,0.5)$ and the complicated interpersonal relationship $\omega=(0.2,0.8)$, which is completely in compliance with the status of the company founder and shows that he has the prominent characteristics of cohesion.

From the perspective of continually changing work environment, when the value of $\omega=\left(\omega_{r}, \omega_{g}\right)$ is different, the core node (02) and (04) are still very stable whether they select node weight sorting or attributes sorting. At the same time, sequence of network structure of executive team in $E$ enterprise is relatively stable under the different relationship orientation, which gives an explanation of the team's strong ability to adapt to the conflict. As a result, it is helpful to provide strong guarantee for the effective operation of the team.

The algorithm for $F$ is similar to foregoing $E$ enterprise. The degree, closeness, cluster coefficient, and betweenness of TMT network in $B$ enterprise are shown in Table 8 . Characteristic attribute matrices $U, V$, and $Y$ and sequence values under different tasks or relations orientation are shown in Tables 9-11.

Similarly, $\omega=(0.5,0.5), \omega=(0.2,0.8)$, and $\omega=(0.8,0.2)$ are used to calculate these attributes for $E$ enterprise. The sequence of characteristic attributes of corporate executives under different condition is as follows: 
TABLE 8: Relationship network characteristic attribute of TMT in $F$ enterprise.

\begin{tabular}{|c|c|c|c|c|c|c|c|}
\hline Name & Number & $F_{B}$ & Degree & Proximity & Cluster coefficient & Betweenness & S-node \\
\hline HWG & 01 & $(14,1,10,9,9,8)$ & $2 r+2 g$ & $14 r+20 g$ & $1 r+1 g$ & $0 r+0 g$ & $20+14$ \\
\hline ZTF & 02 & $(9,2,9,9,8,8)$ & $6 r+5 g$ & $10 r+14 g$ & $0.1333 r+0.3000 g$ & $16 r+17 g$ & $72+60$ \\
\hline SLR & 03 & $(6,2,6,6,7,7)$ & $1 r+2 g$ & $17 r+20 g$ & $0 r+1 g$ & $0 r+0 g$ & $6+21$ \\
\hline WZS & 04 & $(4,2,7,8,8,7)$ & $4 r+2 g$ & $12 r+22 g$ & $0.3333 r+0 g$ & $16 r+12 b$ & $48+6$ \\
\hline $\mathrm{XJ}$ & 05 & $(2,2,3,6,6,7)$ & $2 r+1 g$ & $18 r+29 g$ & $1 r+0 g$ & $0 r+0 b$ & $12+2$ \\
\hline $\mathrm{XHJ}$ & 06 & $(5,1,5,8,8,9)$ & $2 r+2 g$ & $18 r+17 g$ & $1 r+0 g$ & $0 r+22 g$ & $12+10$ \\
\hline CJZ & 07 & $(4,2,2,7,8,8)$ & $2 r+2 g$ & $16 r+20 g$ & $1 r+1 g$ & $0 r+0 g$ & $16+16$ \\
\hline LHF & 08 & $(12,1,6,8,9,8)$ & $2 r+3 g$ & $16 r+16 g$ & $1 r+0.6667 g$ & $0 r+1 g$ & $16+30$ \\
\hline HAP & 09 & $(10,1,7,7,8,8)$ & $1 r+3 g$ & $17 r+14 g$ & $0 r+0.3333 g$ & $0 r+26 g$ & $6+30$ \\
\hline
\end{tabular}

TABLE 9: Relationship network attribute decision matrix and sequence $\omega=(0.5,0.5)$ of TMT in $F$ enterprise.

\begin{tabular}{|c|c|c|c|c|c|c|c|c|c|c|c|c|c|}
\hline \multirow{2}{*}{ Number } & \multicolumn{4}{|c|}{$U$} & \multicolumn{4}{|c|}{ V } & \multicolumn{4}{|c|}{$Y$} & \multirow{2}{*}{ Order } \\
\hline & $D$ & $P$ & C & $B$ & D & $P$ & C & B & $D$ & $P$ & C & $B$ & \\
\hline 01 & 2 & 17 & 1 & 0 & 0.13 & 0.57 & 1 & 0 & 0.0605 & 0.0950 & 0.2464 & 0 & 1.7548 \\
\hline 02 & 5.5 & 12 & 0.22 & 16.5 & 1 & 1 & 0.06 & 1 & 0.4650 & 0.1666 & 0.0148 & 0.2994 & 2.5516 \\
\hline 03 & 10.5 & 18.5 & 0.50 & 0 & 0 & 0.43 & 0.40 & 0 & 0 & 0.0717 & 0.0985 & 0 & 1.0737 \\
\hline 04 & 3 & 17 & 0.17 & 14 & 0.38 & 0.57 & 0 & 0.85 & 0.1767 & 0.0950 & 0 & 0.2545 & 1.9144 \\
\hline 05 & 1.5 & 23.5 & 0.50 & 0 & 0 & 0 & 0.40 & 0 & 0 & 0 & 0.0985 & 0 & 0.5589 \\
\hline 06 & 2 & 17.5 & 0.50 & 11 & 0.13 & 0.52 & 0.40 & 0.67 & 0.0605 & 0.0867 & 0.0985 & 0.2006 & 2.2679 \\
\hline 07 & 2 & 18 & 1 & 0 & 0.13 & 0.48 & 1 & 0 & 0.0605 & 0.0800 & 0.2463 & 0 & 1.7313 \\
\hline 08 & 2.5 & 16 & 0.83 & 0.5 & 0.25 & 0.65 & 0.80 & 0.03 & 0.1163 & 0.1083 & 0.1970 & 0.0090 & 2.1322 \\
\hline 09 & 2 & 15.5 & 1.3 & 13 & 0.13 & 1.78 & 0 & 0.79 & 0.0605 & 0.2967 & 0 & 0.2365 & 1.9334 \\
\hline
\end{tabular}

The value of weight of OWG is $0.2481,0.2519,0.2511$, and 0.2489 ; the sequence is $02>06>08>09>04>01>07>03>05$.

TABLE 10: Relationship network attribute decision matrix and sequence $\omega=(0.2,0.8)$ of TMT in $F$ enterprise.

\begin{tabular}{|c|c|c|c|c|c|c|c|c|c|c|c|c|c|}
\hline \multirow{2}{*}{ Number } & \multicolumn{4}{|c|}{$U$} & \multicolumn{4}{|c|}{ V } & \multicolumn{4}{|c|}{$Y$} & \multirow{2}{*}{ Order } \\
\hline & $D$ & $P$ & C & $B$ & $D$ & $P$ & $C$ & $B$ & $D$ & $P$ & $C$ & $B$ & \\
\hline 01 & 2 & 20.8 & 1 & 0 & 0.20 & 0 & 1 & 0 & 0.0714 & 0 & 0.2392 & 0 & 1.2157 \\
\hline 02 & 5.2 & 13.2 & 0.27 & 16.8 & 1 & 1 & 0.09 & 0.81 & 0.3572 & 0.2330 & 0.0215 & 0.2440 & 2.5535 \\
\hline 03 & 1.8 & 19.4 & 0.8 & 0 & 0.15 & 0.18 & 0.75 & 0 & 0.0536 & 0.0420 & 0.1795 & 0 & 1.5823 \\
\hline 04 & 2.4 & 20 & 0.67 & 12.8 & 0.30 & 0.24 & 0.59 & 0.62 & 0.1071 & 0.0559 & 0.1411 & 0.1867 & 2.3281 \\
\hline 05 & 1.2 & 15.2 & 0.2 & 0 & 0 & 0.74 & 0 & 0 & 0 & 0.1725 & 0 & 0 & 0.6430 \\
\hline 06 & 2 & 17.2 & 0.2 & 17.6 & 0.20 & 0.47 & 0 & 0.85 & 0.0714 & 0.1096 & 0 & 0.2560 & 1.8034 \\
\hline 07 & 2 & 19.2 & 1 & 0 & 0.20 & 0.21 & 1 & 0 & 0.0714 & 0.0490 & 0.2393 & 0 & 1.6844 \\
\hline 08 & 2.8 & 16 & 0.73 & 0.8 & 0.40 & 0.63 & 0.66 & 0.04 & 0.1429 & 0.1469 & 0.1579 & 0.0120 & 2.1958 \\
\hline 09 & 2.6 & 14.6 & 0.27 & 20.8 & 0.35 & 0.82 & 0.09 & 1 & 0.1250 & 0.1911 & 0.0215 & 0.3013 & 2.3791 \\
\hline
\end{tabular}

The value of weight of OWG is $0.2502,0.2513,0.2502$, and 0.2483 ; the sequence is $02>09>04>08>06>07>03>01>05$.

When $\omega=(0.5,0.5)$, order relation of attributes is 02 $>06>08>09>04>01>07>03>05$ and order relation of node weight is $02>04>08>09>01>07$ $>03>06>05$.

When $\omega=(0.2,0.8)$, order relation of attributes is 02 $>09>04>08>06>07>03>01>05$ and order relation of node weight is $02>08>09>03>07>01$ $>04>06>05$.

When $\omega=(0.8,0.2)$, order relation of attributes is 04 $>02>06>09>08>01>07>05>03$ and order relation of node weight is $02>04>01=08>07>06$ $>09>05>03$.
In the different value of $\omega=\left(\omega_{r}, \omega_{g}\right)$, traits of node 01 (CEO) ranks behind others in the network position and at the same time node 01 is excluded from key nodes. As the key leader of a team, node 01 has a poor performance in work instruction, interpersonal communication, and leadership. The chairman is unable to fulfill his duty, which will trigger conflict.

Viewing the situation as a whole, under different relationship status, the performance of professional managers (nodes $03,05,06$, and 07 ) is just mediocre, except node 04 . This company will lose its advantages. And the length of the path between general manager (node 01) and members (nodes 04, 
TABLE 11: Relationship network attribute decision matrix and sequence $\omega=(0.8,0.2)$ of TMT in $F$ enterprise.

\begin{tabular}{|c|c|c|c|c|c|c|c|c|c|c|c|c|c|}
\hline \multirow{2}{*}{ Number } & \multicolumn{4}{|c|}{$U$} & \multicolumn{4}{|c|}{ V } & \multicolumn{4}{|c|}{$Y$} & \multirow{2}{*}{ Order } \\
\hline & $D$ & $P$ & C & $B$ & $D$ & $P$ & C & $B$ & $D$ & $P$ & C & $B$ & \\
\hline 01 & 2 & 15.2 & 1 & 0 & 0.17 & 0.53 & 1 & 0 & 0.0702 & 0.1345 & 0.1923 & 0 & 1.7787 \\
\hline 02 & 5.8 & 10.8 & 0.17 & 16.2 & 1 & 1 & 0 & 1 & 0.4132 & 0.2538 & 0 & 0.3936 & 2.3045 \\
\hline 03 & 1.2 & 17.6 & 0.20 & 0 & 0 & 0.28 & 0.04 & 0 & 0 & 0.0711 & 0.0077 & 0 & 0.8066 \\
\hline 04 & 3.6 & 14 & 0.27 & 15.2 & 0.52 & 0.66 & 0.12 & 0.94 & 0.2150 & 0.1675 & 0.0231 & 0.3701 & 2.4885 \\
\hline 05 & 1.8 & 20.2 & 0.80 & 0 & 0.13 & 0 & 0.76 & 0 & 0.0537 & 0 & 0.1462 & 0 & 1.0986 \\
\hline 06 & 2 & 17.8 & 0.80 & 4.4 & 0.17 & 0.26 & 0.76 & 0.27 & 0.0702 & 0.0660 & 0.1462 & 0.1063 & 2.2110 \\
\hline 07 & 2 & 16.8 & 1 & 0 & 0.17 & 0.36 & 1 & 0 & 0.0702 & 0.0914 & 0.1923 & 0 & 1.7228 \\
\hline 08 & 2.2 & 16 & 0.93 & 0.2 & 0.22 & 0.45 & 0.92 & 0.01 & 0.0909 & 0.1142 & 0.1768 & 0.0040 & 2.0311 \\
\hline 09 & 1.4 & 16.4 & 0.67 & 5.5 & 0.04 & 0.40 & 0.60 & 0.32 & 0.0165 & 0.1015 & 0.1154 & 0.1260 & 2.1015 \\
\hline
\end{tabular}

The value of weight of OWG is $0.2491,0.2523,0.2520$, and 0.2466 ; the sequence is $04>02>06>09>08>01>07>05>03$.

05, and 06) is long, which results in the lack of cohesion in the team and possible factional conflicts; meanwhile, the sequence of relation network of senior team members changes frequently. And the performance of members is poor to reduce team conflict, which leads to significant negative effects on team efficiency under the different relationship oriented.

Then we make a comparison between teams $E$ and $F$ of sequence changes of attributes and find that attribute order of members of top management team $E$ keeps stable and it also keeps the strong ability to deal with conflict even under the relatively high level of conflicts. Besides, core members in TMT (nodes 02 and 04) have a great performance and play a key role no matter under what kinds of conflicts. Nevertheless, attribute order of members of team $F$ is volatile under different level of conflicts. For example, node 02 as a vice general manager of family tends to be highly centralized and core members cannot be stable. As a result, the relationship among team is more complex. Besides, the conflicts among family members and external professional managers seriously damage the TMT's cohesion. Additionally, it can be found easily that the change of conflict intensity will exert a profound influence on the relationship between member $i$ and $j$ by researching static characteristics of network of the team under the different level of conflict. This relationship will reflect external smooth communication, polymerization degree between two nodes, the cohesion of core members, and obvious team characteristics.

\section{Conclusions}

Completely rational actor is inexistent in the real world; in addition to the fact that information between the TMT members of the family enterprise is not completely transparent, the personality characteristics and the emotion of the executing task also affect the learning and decision making process. The conflict between team members is complex management problems; it has a nonlinear characteristic. On the basis of research above, it is well founded to think that different conflict will influence the relationship between team members. In other words, it will bring changes about communication between members. And these changes will affect the cohesion in TMT. At the same time, as a key factor, team leadership plays the significant role in the conflict. Results calculated with complex network model and results of interview are well corroborated mutually.

Firstly, only the manager who grasps the nature of team conflict comprehensively and who uses a variety of conflict management styles can deal with conflicts effectively and enhance the frequency of cooperation and improve team cohesion. Secondly, in order to maximize the overall interests of enterprises, enterprise managers should focus on strengthening unity and cooperation among team members, controlling the intensity of conflict between team members at a reasonable level, finding out primary causes of conflict, and clearing conflict of nature. Using different strategies of avoiding conflict can achieve contradictory unity between individual and team efficiency, effectively enhance cohesion of team, and build a harmonious team. Finally, these results show us that a fast and effective research program for the network study of conflicts in TMT under the complex environments will be provided if we analyze and extract the network characteristic attributes which are degree, closeness, cluster coefficient, and betweenness and aggregate the value of them with the help of the relevance between traits of management team and complex network characteristics on the basis of building the model of network [25-27].

\section{Conflict of Interests}

The authors declare that there is no conflict of interests regarding the publication of this paper.

\section{Acknowledgments}

This research is supported by National Natural Science Fund (71102160), Humanities and Social Sciences Project of Ministry of Education (10YJC630281), China Postdoctoral Science Foundation funded project (2015M571708), and Advanced Talent Project of Jiangsu University (09JDG050 and 14JDG202), and National Statistic Fund (2014LY071).

\section{References}

[1] K. A. Jehn, G. B. Northcraft, and M. A. Neale, "Why differences make a difference: a field study of diversity, conflict, and 
performance in work groups," Administrative Science Quarterly, vol. 44, no. 4, pp. 741-763, 1999.

[2] J. A. Chatman and F. J. Flynn, "The influence of demographic heterogeneity on the emergence and consequences of cooperative norms in work teams," Academy of Management Journal, vol. 44, no. 5, pp. 956-974, 2001.

[3] M. Kilduff, R. Angelmar, and A. Mehra, “Top managementteam diversity and firm performance: examining the role of cognition," Organization Science, vol. 11, no. 1, pp. 21-34, 2000.

[4] A. C. Amason, "Distinguishing the effects of functional and dysfunctional conflict on strategic decision making: resolving a paradox for top management teams," Academy of Management Journal, vol. 39, no. 1, pp. 123-148, 1996.

[5] B. Bollobas, Modern Graph Theory, Springer, New York, NY, USA, 2001.

[6] D. Breuker, P. Delfmann, H.-A. Dietrich, and M. Steinhorst, "Graph theory and model collection management: conceptual framework and runtime analysis of selected graph algorithms," Information Systems \& e-Business Management, vol. 13, no. 1, pp. 69-106, 2015.

[7] R. A. Brualdi, Introductory Combinatorics, Pearson, New York, NY, USA, 2009.

[8] M. A. Chase, C. D. Lirgg, and D. L. Feltz, "Do coaches' efficacy expectations for their predict team performance?" The Sports Psychologist, vol. 11, no. 1, pp. 8-23, 1997.

[9] J. Luo D, S. C. Chi, and D. Lin, "Who is trust worthy: a comparison of social relation across the Taiwan strait," in Proceedings of the Conference of North American Chinese Sociologists Association, Chicago, Ill, USA, 2002.

[10] R. M. Stogdill, Manual for the Leader Behavior Description Questionnaire-Form XII, Ohio State University, Bureau of Business Research, Columbus, Ohio, USA, 1963.

[11] M. D. Michalisin, S. J. Karau, and C. Tangpong, "Top management team cohesion and superior industry returns: an empirical study of the resources-based view," Group \& Organization Management, vol. 29, no. 1, pp. 125-140, 2004.

[12] D. C. Hambrick, S. E. Humphrey, and A. Gupta, "Structural interdependence within top management teams: a key moderator of upper echelons predictions," Strategic Management Journal, vol. 36, no. 3, pp. 449-461, 2015.

[13] L. C. Freeman, "A set of measures of centrality based on betweenness," Sociometry, vol. 40, no. 1, pp. 35-41, 1977.

[14] H. Zare, A. Mohammadpour, and P. Moradi, "A random projection approach for estimation of the betweenness centrality measure," Intelligent Data Analysis, vol. 17, no. 2, pp. 217-231, 2013.

[15] M. Shanahan and M. Wildie, "Knotty-centrality: finding the connective core of a complex network," PLoS ONE, vol. 7, no. 5, Article ID e36579, 2012.

[16] S. Wasserman, Social Network Analysis, Cambridge University Press, Cambridge, UK, 1994.

[17] X. Gu, "A kind of trust calculation model among nodes in wireless sensor networks," ICIC Express Letters, vol. 6, no. 7, pp. 1821-1826, 2012.

[18] J. An, X. Gui, W. Zhang, J. Jiang, and J. Yang, "Research on social relations cognitive model of mobile nodes in Internet of Things," Journal of Network and Computer Applications, vol. 36, no. 2, pp. 799-810, 2013.

[19] M. A. Rahim, "Toward a theory of managing organizational conflict," The International Journal of Conflict Management, vol. 13, no. 3, pp. 206-235, 2002.
[20] D. R. Deeter-Schmelz and K. N. Kennedy, "Patient care teams and customer satisfaction: the role of team cohesion," The Journal of Services Marketing, vol. 17, no. 6-7, pp. 666-684, 2003.

[21] K. A. Jehn and E. A. Mannix, "The dynamic nature of conflict: a longitudinal study of intragroup conflict and group performance," Academy of Management Journal, vol. 44, no. 2, pp. 238-251, 2001.

[22] M. D. Ensley, A. W. Pearson, and A. C. Amason, "Understanding the dynamics of new venture top management teams cohesion, conflict, and new venture performance," Journal of Business Venturing, vol. 17, no. 4, pp. 365-386, 2002.

[23] P. D. Turman, "Coaches and cohesion: the impact of coaching techniques on team cohesion in the small group sport setting," Journal of Sport Behavior, vol. 26, no. 1, pp. 86-104, 2003.

[24] J. Mathieu, T. M. Maynard, T. Rapp, and L. Gilson, “Team effectiveness 1997-2007: a review of recent advancements and a glimpse into the future," Journal of Management, vol. 34, no. 3, pp. 410-476, 2008.

[25] T. Kelepouris, P. Miliotis, and K. Pramatari, "The impact of replenishment parameters and information sharing on the bullwhip effect: a computational study," Computers \& Operations Research, vol. 35, no. 11, pp. 3657-3670, 2008.

[26] Y. Lin, K. C. Desouza, and S. Roy, "Measuring agility of networked organizational structures via network entropy and mutual information," Applied Mathematics and Computation, vol. 216, no. 10, pp. 2824-2836, 2010.

[27] D. Tjosvold, C. Hui, D. Z. Ding, and J. Hu, "Conflict values and team relationships: conflict's contribution to team effectiveness and citizenship in china," Journal of Organizational Behavior, vol. 24, no. 1, pp. 69-88, 2003. 


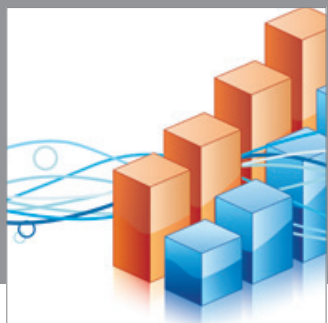

Advances in

Operations Research

mansans

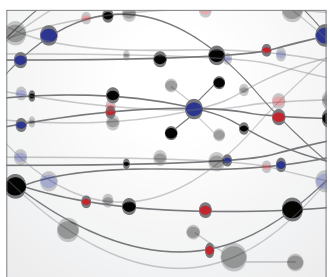

The Scientific World Journal
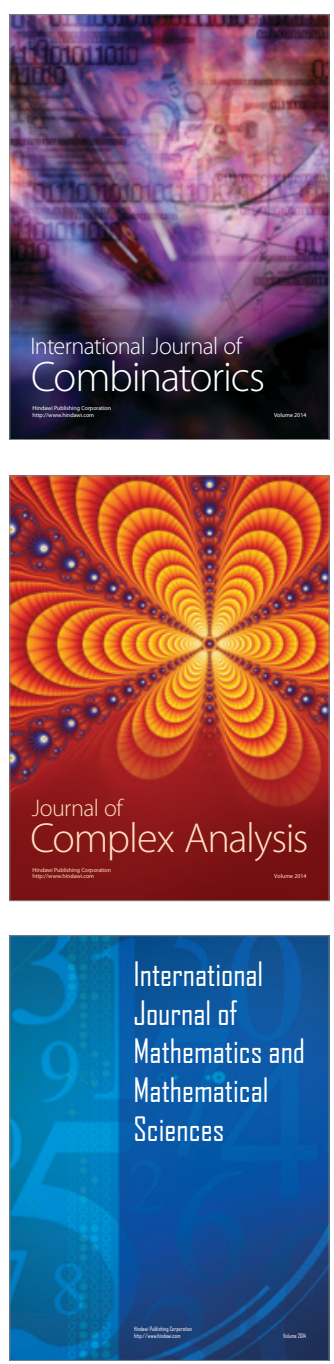
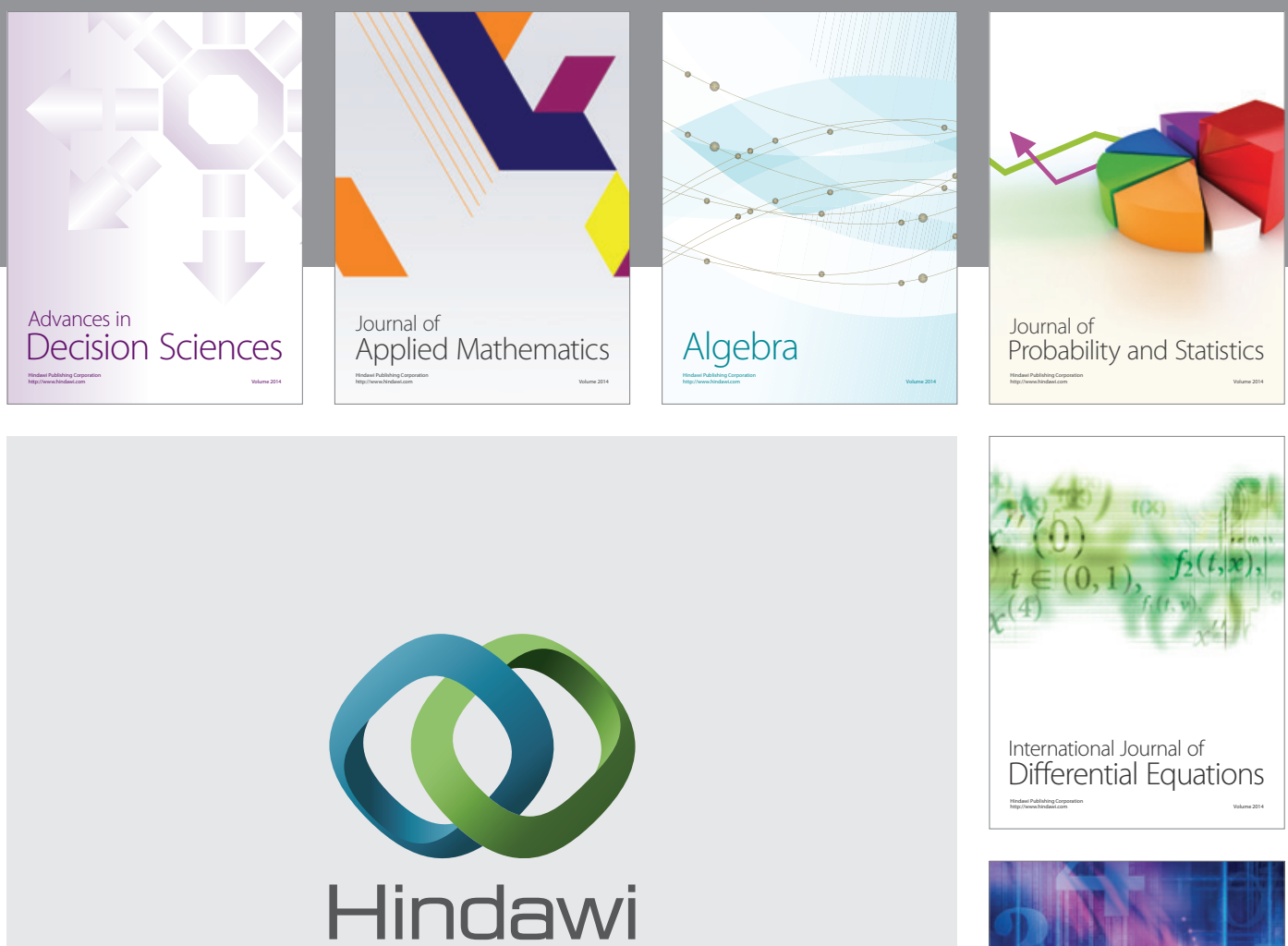

Submit your manuscripts at http://www.hindawi.com
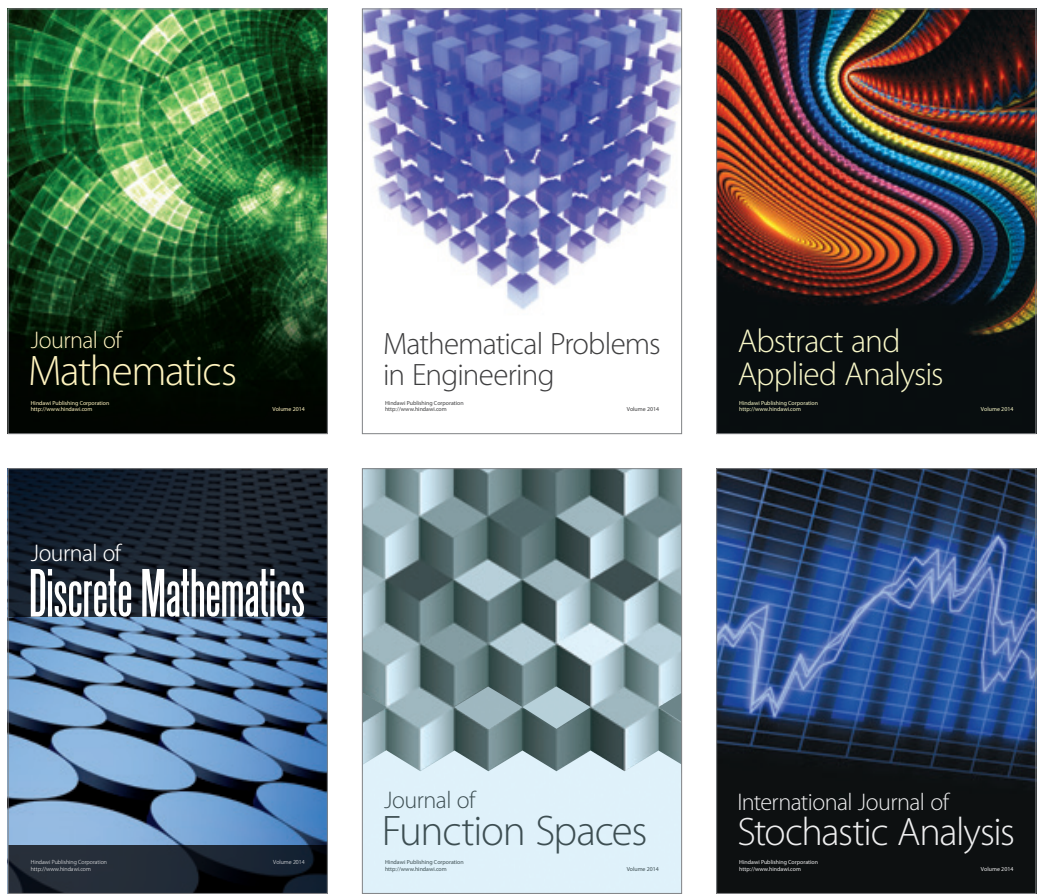

Journal of

Function Spaces

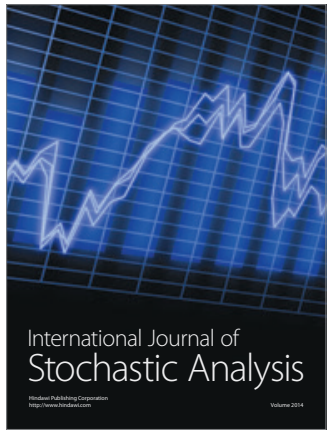

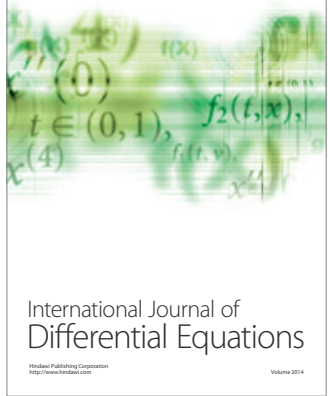
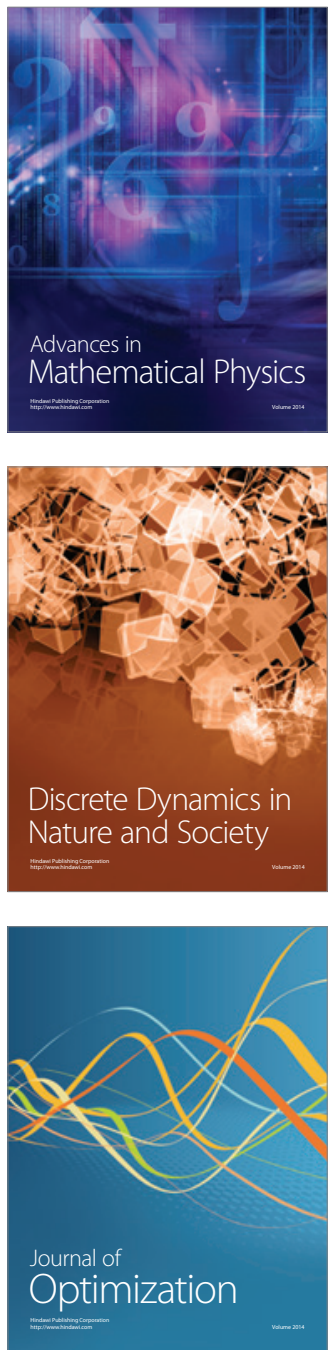